\title{
MOGUĆNOSTI I OGRANIČENJA ZA IZDVAJANJE PLEMENITIH METALA IZ ELEKTRONSKOG OTPADA
}

\section{POSSIBILITIES AND LIMITATIONS FOR THE EXTRACTION OF PRECIOUS METALS FROM ELECTRONIC WASTE}

\author{
Milica Čekić, Bojan Batinić, Fakultet tehničkih nauka, Novi Sad
}

\section{Oblast - INŽENJERSTVO ZAŠTITE ŽIVOTNE SREDINE}

Kratak sadržaj -U ovom radu date su osnovne definicije elektronskog otpada, količnie, sastav i njegov uticaj na životnu sredinu. Obuhvaćene su i zakonske regulative $u$ Evropskoj uniji i Srbiji. Opisana je upotreba plemenitih metala u elektronskoj opremi. Glavni deo rada predstavljaju metode izdvajanja plemenitih metala iz elektronske opreme, gde je obuhvaćena reciklaža, sakupljanje, prethodna obrada $i$ završna obrada. Na kraju rada prikazani su ograničavajući faktori izdvajanja plemenitih metala iz elektronskog otpada.

Ključne reči: e-otpad, recikaža, plemeniti metali, izdvajanje plemenitih metala

\begin{abstract}
In this paper the basic definitions of electronic waste, quantity, composition and its impact on the environment are given. Legislation in the European Union and Serbia is also covered. The use of precious metals in electronic equipment is described. The main part of the paper is the method of extraction of precious metals from electronic equipment, which includes recycling, collection, pretreatment and final treatment. At the end of the paper, limiting factors for the extraction of precious metals from electronic waste are shown..
\end{abstract}

Keywords: e-waste, recycling, precious metals, extraction of precious metals

\section{UVOD}

Proizvodnja električne i elektronske opreme je jedna od najbrže rastućih globalnih proizvodnih aktivnosti. Drastične inovacije na električnim i elektronskim tehnologijama dodatno su smanjile životni vek i time povećale proizvodnju otpada od električne i elektronske opreme. Otpad od električne i elektronske opreme može biti izvor opasnog otpada koji predstavlja rizik za životnu sredinu i održiv ekonomski rast [1]. Trenutno se na globalnom nivou generiše od 20 do 25 miliona tona e-otpada sa najvećim udelom Evrope, SAD i Australije. Međutim, očekuje se da Kina, Istočna Evropa i Latinska Amerika postanu značajni proizvođači e-otpada u narednoj deceniji [2]. E-otpad sadrži plemenite metale, uključujući zlato $(\mathrm{Au})$, srebro $(\mathrm{Ag})$, platinu $(\mathrm{Pt})$, paladijum $(\mathrm{Pd})$ i druge, ali sadrži i vredne teške materijale kao što su gvožđe $(\mathrm{Fe})$ i

\section{NAPOMENA:}

Ovaj rad proistekao je iz master rada čiji mentor je bio doc. dr Bojan Batinić. aluminijum (Al), zajedno sa plastičnim materijalima koji se mogu reciklirati. Plemeniti metali, imaju kapacitet da se recikliraju beskonačno [3]. Recikliranje otpadne električne i elektronske opreme važno je ne samo za smanjenje količine otpada koji zahteva tretman, već i za promovisanje ekstrakcije vrednih materijala.

\section{ELEKTRONSKI OTPAD I NJEGOV SASTAV}

Prema pravilniku o upravljanju otpadom od električnih i elektronskih proizvoda ("Sl. glasnik RS", br. 99/2010) električna i elektronska opremu (e-oprema) su proizvodi čiji pravilan rad zavisi od električne struje i elektromagnetnog polja, kao i oprema koja je namenjena za proizvodnju, prenos i merenje struje ili za merenje jačine elektromagnetnog polja i namenjena je korišćenju pri naponu koji ne prelazi $1000 \mathrm{~V}$ za naizmeničnu i 1500 V za jednosmernu struju [4]. Prema Zakonskoj regulativi Evropskog Parlamenta 2002/96/EC, elektronski i električni uređaju su klasifikovani u 10 kategorija (razreda) opreme:

1. Veliki kućni aparati;

2. Mali kućni aparati;

3. Oprema informatičke tehnologije (IT) i telekomunikacije (TT);

4. Oprema široke potrošnje za razonodu i fotonaponske ćelije;

5. Oprema za osvetljavanje;

6. Električni i elektronski alati (osim velikih nepokretnih industrijskih alata);

7. Igračke, oprema za rekreaciju i sport;

8. Medicinski pomoćni uredaji (osim implantiranih i infektivnih proizvoda);

9. Instrumenti za praćenje i nadzor;

10. Automati.

Na osnovu podataka iz Nacionalne strategije za upravljanje otpadom, osnovnog strateškog dokumenta koji reguliše ovu oblast, na nivou države Srbije se godišnje generiše najmanje 30.000 tona e-otpada. Najveća količina e-otpada po stanovniku (15,6 kg / st.) generisana je u Evropi. Najmanja količina e-otpada po stanovniku proizvedena je u Africi, gde je svega 1,7 kg / st. proizvedeno 2014 . godine. Amerike su generirale 11,7 miliona tona e-otpada (7,9, 1,1 i 2,7 miliona tona za Severnu Ameriku, Centralnu Ameriku i Južnu Ameriku), što je predstavljalo $12,2 \mathrm{~kg} / \mathrm{st}$ [5]. U prosečan sastav e-otpada ulaze sledeće komponente: metali $-60 \%$, polutanti - 3\%, štampane ploče - $2 \%$, CTR i LCD monitori - $12 \%$, kablovi $-2 \%$, smeša plastike i metala $-5 \%$, plastika $-15 \%$ i ostalo $1 \%$ [6]. E-otpad se sastoji se od višestrukih komponenti 
od kojih neki sadrže toksične supstance koje imaju negativan uticaj na ljudsko zdravlje i životnu sredinu, ako se ne postupa pravilno sa njima, odnosno ako se koriste neadekvatne metode recikliranja i odlaganja. U tom kontekstu treba razlikovati tri nivoa toksičnih emisija [7]: - Primarne emisije: Opasne materije koje sadrže e-otpad (npr. Olovo, živa, arsen, polihlorovani bifenili (PCB Polychlorinated biphenyl), fluorirano hlađenje tečnosti itd.).

- Sekundarne emisije: proizvodi opasnih reakcija otpadnih materija kao rezultat nepravilnog tretmana (npr. Dioksini ili furani nastali spaljivanjem / neodgovarajućim topljenjem plastike sa halogenim retardantima).

- Tercijarne emisije: Opasne materije ili reagensi koji se koriste tokom reciklaže (npr. Cijanid ili drugi agensi za ekstrakciju, živa za amalgamaciju zlata) i koji se otpuštaju zbog neadekvatnog rukovanja i tretmana.

\section{ZAKONSKA REGULATIVA U EVROPSKOJ UNIJI I SRBIJI}

WEEE Direktiva 2002/96 / EC je potpisana 27. januara 2003. godine i objavljena je 13. februara 2003. godine. Osnovne svrhe WEEE Direktive 2002/96 / EC bile su sprečavanje proizvodnje WEEE - Waste Electrical and Electronic Equipment i, pored toga, poboljšanje ponovne upotrebe, reciklaže i izdvajanja otpada od električne i elektronske opreme, umesto odlaganja, kako bi se smanjili uticaji na životnu sredinu i zdravlje [8].

RoHS direktiva - Zakonodavstvo EU koje ograničava upotrebu opasnih supstanci u električnoj i elektronskoj opremi (Direktiva RoHS 2002/95 / EC) stupilo je na snagu u februaru 2003. godine. Zakonodavstvo zahteva teške metale kao što su olovo, živa, kadmijum i heksavalentni hrom i retardanti, kao što su polibromirani bifenili (PBB) ili polibromirani difenil etri (PBDE) biće zamenjeni sigurnijim alternativama [9].

Osnovni zakoni i podzakonska akta kojima je regulisana oblast reciklaže elektronskog i električnog otpada u Srbiji su:

- Zakon o upravljanju otpadom

- Pravilnik o listi električnih i elektronskih proizvoda, merama zabrane i ograničenja korišćenja električne i elektronske opreme koja sadrži opasne materije i načinu i postupku upravljanja otpadom od električnih i elektronskih proizvoda

- Uredba o proizvodima koji posle upotrebe postaju posebni tokovi otpada

\section{UPOTREBA PLEMENITIH METALA U ELEKTRONSKOJ OPREMI}

Plemeniti metali pronalaze širok spektar primene $u$ električnoj i elektronskoj opremi, odnosno PCB-ovima za mobilne telefone, medicinskoj opremi, prekidačima, konektorima itd. [10]. Paladijum se široko koristi u primeni elektronskih uređaja zbog električne provodljivosti i trajnosti. Najveća oblast upotrebe paladijuma u sektoru elektronike nalazi se u višeslojnim keramičkim (čip) kondenzatorima (MLCC - Mikro olovni nosač čipova [11]. Zlato se koristi u konektorima, prekidačima, lemljenim spojevima, veznim žicama i vezanim trakama. Mala količina zlata se koristi u skoro svakom sofisticiranom elektronskom uređaju [12].

Tradicionalno, platina se koristi u termozlektričnim uređajima koji mere temperature sa visokom preciznošću. Platina se takođe koristi u žicama i električnim kontaktima za upotrebu u korozivnim ili visokonaponskim okruženjima [13]. Upotreba srebra u elektronskoj i električnoj opremi je široko rasprostranjena i značajan i rastući izvor potražnje. Kontakti, prekidači kola, prekidači i osigurači su nekolicina od više od desetine električnih komponenti koje koriste srebro koje se proizvode u elektro industriji [14].

\section{METODE IZDVAJANJA PLEMENITIH METALA IZ ELEKTRONSKOG OTPADA}

Reciklažom e-otpada se sprečava zagađivanje prirode opasnim i otrovnim elementima i drastično smanjuje količina otpada koja se mora konačno odložiti na deponije, čime se vek iskorišćenja postojećih deponija praktično udvostručuje a i smanjuje potreba za izgradnjom novih [15].

Recikliranje e-otpada sastoji se od tri glavna koraka:

1. sakupljanje,

2. prethodna obrada

3. i završna obrada.

Svaki korak je kritičan za izdvajanje metala i ekonomiju recikliranja [16].

Sakupljanje i transport su dve početne faze procesa reciklaže e-otpada. Recikleri postavljaju kante za sakupljanje ili kontejnere za odlaganje na određenim lokacijama i transportuju prikupljeni e-otpad sa ovih lokacija do postrojenja i objekata za reciklažu.

Prethodna obrada e-otpada je jedan od najvažnijih koraka u lancu reciklaže. U prethodnu obradu spadaju: sortiranje i demontaža; mehanički proces (smanjenje veličine + ručno sortiranje); vibraciono sito; magnetna separacija; separacija vrtložnog toka struje (Eddy current separation); separacija gustine i odlaganje.

Frakcije plemenitih metala, odvojene od otpada u toku prethodne obrade, mogu se dalje obraditi pomoću pirometalurgije, hidrometalurgije, i biometalurgije [17].

Pirometalurgija, energetski intenzivan i skupi proces, predstavlja tradicionalni pristup za izdvajanje metala iz otpadnih PCB-a; ali selektivno izdvajanje pojedinih metala teško može da se uradi ovim putem. Pirometalurški procesi uključuju spaljivanje, topljenje u plazmenoj lučnoj peći ili visokoj peći, prskanje, sinterovanje, topljenje i reakcije u gasnoj fazi na visokim temperaturama [18].

Primarne i sekundarne topionice bakra služe da recikliraju i izvlače plemenite metale iz e-otpada. U topionicama na bazi sumpora (primarno bakarno topljenje), bakarni mat $40 \%$ (Bakarni mat je mešavina bakar sulfida i nekih sulfida gvožđa ) i blister bakar - 98,5\% (delimično prečišćeni bakar sa blistavom površinom formiranom tokom topljenja) se proizvode. Konačno, blister bakar se prečišćava vatrom za proizvodnju čistog bakra. U crnom bakru (sekundarni topionici bakra), sirovi bakar se proizvodi tokom procesa smanjenja i prečišćava se oksidacijom u konvertoru. Crni bakar je atraktivan jer može primiti visoke nivoe nečistoća uključujući Fe, Zn, $\mathrm{Pb}$ i Sn. Ove nečistoće uklanjaju se oksidacijom. Proces 
topljenja bakra sastoji se procesa redukcije i oksidacije. Nečistoće se uglavnom odvajaju u fazu isparavanja ispuštaju se u gasu [19].

U poređenju sa pirometalurškim procesima, hidrometalurški metod je tačniji, predvidljiviji i lakše kontrolisan [20]. Rastvarači, posebno halidi, cijanidi, tiourea i tiosulfati, koriste se za ekstrakcija plemenitih metala iz njihovih primarnih ruda. Izdvajanje plemenitih metala iz izlučenog rastvora se vrši cementacijom, ekstrakcijom rastvarača, adsorpcijom na aktivnom uglju i metodama razmene jona [21].

Kineski patent od strane Zhou i sar. [22] opisuje postupak za izdvajanje plemenitih metala (Ag, $\mathrm{Au}, \mathrm{Pd})$ iz elektronskog otpada koji sadrži plastiku. Otpad se zagreva na $400-500{ }^{\circ} \mathrm{C}$ u trajanju od 8-12 sati da bi se zapalila plastika, a ostatak sirovog metala tretiran je sa $\mathrm{HCl}$ ili $\mathrm{H}_{2} \mathrm{SO}_{4}$ na $90{ }^{\circ} \mathrm{C}$ da bi se rastvorili osnovni metali. Nakon filtracije, ostatak je ispran u razblaženom $\mathrm{HNO}_{3}$ sa odnosom čvrste / tečne faze 1: 2 na $60{ }^{\circ} \mathrm{C}$ da bi se rastvorilo srebro.

$\mathrm{Na}$ kraju, rastvori $\mathrm{HCl}$ i $\mathrm{NaClO}_{3}$ korišćeni su za ekstrakcija zlata i paladijuma. Saopšteno je da izdvajanje plemenitih metala može biti veći od $92 \%$.

Postoje dve glavne oblasti biometalurgije za izdvajanje metala, odnosno bioekstrakcija (bioleaching) i biosorpcija. Bioekstrakcija je uspešno primenjena $u$ preradi metala od metalnih sulfida, koji su glavni minerali za mnoge bazne i plemenite metale, primenom bakteriološki reakcija [23]. Proces biosorpcije je pasivna fizičko-hemijska interakcija između tretiranih površinskih grupa mikroorganizama $\mathrm{i}$ jona $\mathrm{u}$ rastvoru, u kojem se mogu koristiti i živi, ali i mrtvi organizmi.

\section{Bioekstrakcija metala iz elektronskog otpada}

Faramarzi i sar. [24] su saopštili svoj preliminarni uviđaj o izvodljivosti izdvajanja zlata iz štampanih ploča procesom bioekstrakcije. Materijali koji sadrže zlato (5 mm x $10 \mathrm{~mm}$ ) dobijeni su ručno sečenjem štampanih ploča, a zatim ručnim sortiranjem. Svaki komad sadrži približno $10 \mathrm{mg}$ zlata. Koristeći Chromobacterium violaceum, dokazano je da se zlato može mikrobiološki rastvoriti iz štampanih ploča. Maksimalnom dicianoauratu $\left[\mathrm{Au}(\mathrm{CN})_{2}^{-}{ }^{-}\right]$izmereno odgovara $14.9 \%$ rastvora dodatog zlata na početku.

Mehanizmi biosorpcije plemenitih metala

Spektroskopske studije biosorpcije zlata (III) pomoću otpada obrađene morske alge izvršili su RomeroGonzalez i sar. [25]. Saopšteno je da je koloidni Au koji je na površini obrađenih morskih algi smanjenjem $\mathrm{Au}$ (III) na $\mathrm{Au}(0)$ posmatrao koristeći Elektronski mikroskop za skeniranje okruženja (ESEM) i četiri različite vrste čestica jasno su identifikovane. Merenja EKSAFS-a su pokazala da koloidni Au postoji na površini biosorbenta. Dokazi o redukciji zlata od $\mathrm{Au}$ (III) do $\mathrm{Au}$ (I) i $\mathrm{Au}(0)$ takođe su potvrđeni prema izmerenim rastojanjima veze karakterističnim za metal. Broj koordinacije dobijen od EKSAFS-a pokazao je da je približno 75\% Au na uzorku bilo prisutno u koloidnoj formi, a preostali Au je vezan za S. Predloženi mehanizmi za uklanjanje Au iz rastvora su redukcija $\mathrm{Au}$ vrste po komponentama na površini biosorbenta kako bi se formirao koloidni metal, nakon čega sledi zadržavanje jonskih vrsta Au (I) na mestima koja sadrže sumpor.

\section{OGRANIČENJA IZDVAJANJA PLEMENITIH METALA IZ ELEKTRONSKOG OTPADA}

Nedostatak postrojenja za prikupljanje elektronskog otpada - Sakupljanje e-otpada predstavlja kritičan korak za reciklažu e-otpada i efikasno upravljanje resursima. Što se tiče trenutne situacije vezane za e-otpad u Srbiji ne postoji sistemsko prikupljanje elektronskog otpada.

Nedostatak postrojenja za odvajanje metala iz kompleksnih materijala E-otpada - Trenutno u Srbiji, nalaze se i četiri fabrike za reciklažu električnog i elektronskog otpada. Ono što je zajedničko za sve četiri fabrike, jeste da one vrše reciklažu reciklabilnih elemenata u uređajima kao što su plastika, metal i staklo. Nereciklabilne komponente, kao što su matične ploče, katodne cevi, procesori $\mathrm{i}$ hard diskovi, skladište $\mathrm{u}$ posebnim kontenerima i na kraju ih izvoze u inostranstvo, jer finalno recikiranje obavlja mali broj reciklažnih kompanija u svetu [26].

Nedostatak integrisanih topionica $i$ rafinerijskog postrojenja - U Srbiji postoji jedna topionica bakra $\mathrm{u}$ Boru koja je u funkciji, i topionica olova u Zajači kod Loznice u kojoj se vrši remont i trenutno nije u funkciji. Ovo je značajna prepreka za reciklažu e-otpada u Srbiji.

Čuvanje plemenitih metala - U poslednjih nekoliko godina izbegnuta je upotreba skupih metala, kao što su plemeniti metali, a u nekim slučajevima ovi metali zamenjeni su drugim niskobudžetnim metalima kako bi se smanjili troškovi proizvodnje. Ovo je poželjno u smislu efikasne upotrebe oskudnih resursa; međutim, to može predstavljati nove poslovne rizike za preduzeća za preradu plemenitih metala [27].

Složenost proizvoda - Obično su poznate kombinacije plemenitih metala i drugih elemenata, koje treba da budu odvojene jedni od drugih. Na primer, srebro i paladijum moraju biti odvojeni u slučaju provodnih pasta. Kada se novi element sadrži u prerađivanju otpada, zahvaljujući unapređenju tehnologije, reciklaža i prerada odjednom postaju nemoguće izvesti konvencionalnim metodama i tehnikama [28].

\section{ZAKLJUČAK}

Proizvodnja električne i elektronske opreme jedna je od najbrže rastućih globalnih proizvodnih aktivnosti. Potražnja za električnom i elektronskom opremom drastično se povećala napredovanjem tehnologije. U svetu postoji nezaobilazna potražnja za plemenitim metalima, naročito za zlatom $(\mathrm{Au})$, srebrom $(\mathrm{Ag})$, paladijumom $(\mathrm{Pd})$ i platinom $(\mathrm{Pt})$ i drugim vrednim teškim materijalima kao što su gvožđe (Fe) i aluminijum (Al), zajedno sa plastičnim materijalima koji se mogu reciklirati.

Recikliranje e-otpada je važno za upravljanje resursima i otpadom. Tehnološki napredak mora se posmatrati u vezi sa zaštitom ljudskog zdravlja, ekosistema, čiste tehnologije na oba nivoa: proizvodnja i recikliranje, poboljšanje zakonodavstva $u$ oblasti životne sredine i poboljšane metode recikliranja otpada kao izvora sekundarnih sirovina, izbegavanje emisija i kontaminacija voda, vazduh i zemljišta.

Rešavanjem ograničavajućih faktora u budućnosti moguće je recikliranje e-otpada u Srbiji, čime bi se 
postigla ušteda energije, očuvanje resursa, vrednih i plemenitih metala kao i očuvanje životne sredine.

\section{LITERATURA}

[1] Babu Balakrishnan Ramesh, Anand Kuber Parande and Chiya Ahmed Basha, Electrical and electronic waste: a global environmental problem, 2007

(http://wmr.sagepub.com/content/25/4/307)

[2] Robinson B.H., E-waste: An assessment of global production and environmental impacts. Science of Total Environment 2009; 408: 183-191.

[3] Canda L., Heput T. and Ardelean E., Methods for recovering precious metals from industrial waste, 2016.

[4] Anonim, 2010

[5] Baldé, C.P., Wang, F., Kuehr, R., Huisman, J. (2015), The global e-waste monitor - 2014, United Nations University, IAS - SCYCLE, Bonn, Germany.

[6] Bigum M, Claus Petersen C, Christensen TH, Scheutz C. WEEE and portable batteries in residual household waste: Quantification and characterization of misplaced waste. Waste Management 2013; 33: 2372-2380.

[7] Mahipal Singh Sankhla, Mayuri kumari, Manisha Nandan, Shriyash Mohril, Gaurav Pratap Singh, Bhaskar Chaturvedi, Dr. Rajeev Kumar, Effect of Electronic waste on Environmental \& Human health - A Review, Sep. 2016.

[8] European Commission, "Directive 2002/96/EC of the European Parliament and of the Council of 27 January 2003 on Waste Electrical and Electronic Equipment," Ofcial Journal L 37, 2003.

[9]http://ec.europa.eu/environment/waste/weee/index_en. htm (3.10.2018.)

[10] Baba, H., 1987. An efficient recovery of gold and other noble metals from electronic and other scraps.

Conserv. Recycling 10 (4), 247-252.

[11]http://www.platinum.matthey.com/aboutpgm/applications/industrial/electronic-components (6.10.2018.)

[12]https://geology.com/minerals/gold/uses-of-gold.shtml (6.10.2018.)

[13] https://www.azom.com/article.aspx?ArticleID=1344 (7.10.2018.)

[14] https://www.silverinstitute.org/site/silver-inindustry/electronic/,http://geology.com/metals/ (7.10.2018.)

[15]http://setreciklaza.rs/index.php?option=com_content \&view=article\&id=77\&Itemid=204 (8.10.2018.)

[16] Meskers, C.E.M.; Hagelüken, C.; Salhofer, S.; Spitzbart, M. Impact of Pre-Processing Routes on Precious Metal Recovery from PCs. In Proceedings of the European Metallurgical Conference (EMC), Innsbruck, Austria, 28 June-1 July 2009.

[17]http://www.academia.edu/6209804/Recovery_of_prec ious_metals_from_e-waste (12.10.2018.)

[18] Ropafadzo Jamakanga, Tinevimbo Homero, Tavonga Guzura, Kudakwashe Kanengon, Modamombe Jonathan, Mutauto Effort B, Kurwara Tinotenda, Feasibility study for recovering precious metals from e-waste, 2014. [19] Anindya, A. Minor Elements Distribution during the Smelting of WEEE with Copper Scrap. Ph.D Thesis, RMIT University, Melbourne, Australia, 2012.
[20] Hagelüken, C. Improving Metal Returns and EcoEfficiency in Electronics Recycling-A Holistic Approach for Interface Optimisation between PreProcessing and Integrated Metals Smelting and Refining. In Proceedings of the IEEE International Symposium on Electronics and the Environment, Scottsdale, AZ, USA, 8-11 May 2006.

[21] Khaliq Abdul, Rhamdhani Muhammad Akbar, Brooks Geoffrey and Masood Syed; Metal Extraction Processes for Electronic Waste and Existing Industrial Routes: A Review and Australian Perspective; Faculty of Science, Engineering and Technology, Swinburne University of Technology, Hawthorn, VIC 3122, Australia, 19 February 2014.

[22] Zhou P., Zheng Z., Tie J., Technological process for extracting gold, silver and palladium from electronic industry waste, Chinese Patent, CN1603432A (C22B 11/00) (2005).

[23] Morin D., Lips A., Pinches T., et al., BioMinE Integrated project for the development of biotechnology for metal-bearing materials in Europe, Hydrometallurgy 83 (1-4) (2006) 69-76.

[24] Faramarzi M.A., Stagars M., Pensini E., et al., Metal solubilization from metal-containing solid materials by cyanogenic Chromobacterium violaceum, J. Biotechnol. 113 (1-3) (2004) 321-326.

[25] Romero-Gonzalez M.E., Williams C.J., Gardiner P.H.E., et al., Spectro-' scopic studies of the biosorption of gold(III) by dealginated seaweed waste, Environ. Sci. Technol. 37 (18) (2003) 4163-4169.

[26] https://www.industrija.rs/vesti/clanak/reciklaza-iproblemi-elektronskog-otpada (5.11.2018.)

[27] Kayanuma Yoshihiro, Mizuhashi Shoei and Shindo

Yuichiro, Challenges in the Recycling of Precious Metals, August 25, 2018.

[28] Miura Y.: Materia Japan 46 (2007) 180-183.

\section{Kratka biografija:}

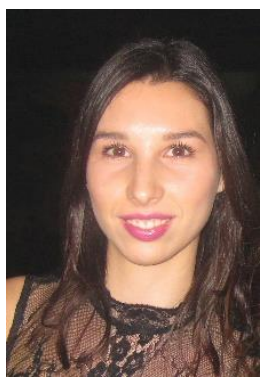

Milica Čekić rođena je 17. maja 1992. godine u Zrenjaninu. Osnovnu školu završila je u Zrenjaninu, kao i srednju HPTŠ „Uroš Predić“, tehničar za biotehnologiju, 2011. godine. Završila je VTŠSS u Zrenjaninu, smer zaštita životne sredine, 2014. godine. Tehnički fakultet „Mihajlo Pupin“ Zrenjan upisala 2015. godine, isti smer i diplomirala 2017. godine. Master studije na Fakultetu tehničkih nauka, smer inžinjerstvo zaštite životne sredine upisala je 2017. godine.

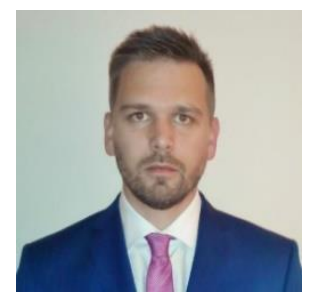

Bojan Batinić rođen je 1981. godine u Zagrebu. Master studije na studijskom programu inženjerstvo zaštite životne sredine na Fakultetu tehničkih nauka iz Novog Sada je završio 2008. godine. Doktorirao je 2015. godine na Fakultetu tehničkih nauka i iste godine izabran je u zvanju Docenta. 